\title{
Spatial distribution and temporal trends of farmland soil PBDEs: processes and crop rotation effects
}

\author{
Xingchun Jiao ${ }^{1}$ - Qifeng Tang ${ }^{1}$ - Shu Chen ${ }^{1}$ - Yajia Deng ${ }^{2} \cdot$ Hongying Cao $^{2}$. \\ Guang Wang ${ }^{1} \cdot$ Yongliang Yang ${ }^{1}$
}

Received: 22 December 2015 / Accepted: 7 March 2016 /Published online: 23 March 2016

(C) Springer-Verlag Berlin Heidelberg 2016

\begin{abstract}
The concentration and temporal trend of PBDEs in farmland soil during a circle of crop rotation period within an e-waste dismantling area of South China were investigated. The averaged current concentration of total PBDEs in the farmland soil was averaged $19.1 \pm 20.7 \mathrm{ng} / \mathrm{g}$ dry weight, which was much lower than the PBDE level in roadside soil and in topsoil near e-waste dismantling sites. Spatial distribution of total PBDEs concentration in the study area showed higher level at the field near e-waste workshops and lower at the distanced farmland area. Soil organic carbon content was significantly correlated with concentration of BDE209 $(r=0.704, p<0.01)$, but not related with the sum concentration of other PBDE compounds $(r=0.097, p>0.1)$. During the whole crop rotation circle, the temporal concentration of PBDEs in the farmland soil was highest $(25.3 \pm 11.4 \mathrm{ng} / \mathrm{g}$ dry wt.) in April when early paddy had been transplanted for 1 or 2 weeks. When the crop rotated to autumn peanut in August and the land is turning dry, the PBDEs concentration in farmland soil reached the lowest level which was 8.1 $\pm 1.2 \mathrm{ng} / \mathrm{g}$ dry wt. The temporal trend of PBDEs in farmland
\end{abstract}

Responsible editor: Hongwen Sun

Electronic supplementary material The online version of this article (doi:10.1007/s11356-016-6442-6) contains supplementary material, which is available to authorized users.

Xingchun Jiao

jiaoxch@pku.edu.cn

1 Key Laboratory of Ministry of Land and Resources for Eco-geochemistry, National Research Center for Geoanalysis, Xicheng District, 26 Baiwanzhuang Street, Beijing 100037, China

2 Institute of Geographic Sciences and Natural Resources Research, Beijing 100101, China soil was not consistent with that of atmospheric PBDEs and soil total organic carbon (TOC) content during the rotation cycle. It was concluded that the dynamics of PBDEs in the farmland soil is influenced by multiple, interacting factors, and not clearly related to neither the atmospheric deposition nor the organic carbon content of the soil, but possibly related to the micro-environmental conditions changed by crop rotation process.

Keywords Polybrominated diphenyl ethers (PBDEs) . Farmland soil · Spatial distribution · Temporal trend · Crop rotation

\section{Introduction}

Polybrominated diphenyl ethers (PBDEs) are used in large quantities to flame retard a variety of consumer products. As the retardants are intentionally added rather than reacted to the materials, they could leach from the products throughout the lifetime of the products (de Wit 2002). After decades of manufacturing and product consuming, PBDEs have now been widely dispersed into the global environment (Alaee et al. 2003; Hassanin et al. 2004; Miglioranza et al. 2013). Studies indicated increasing level of PBDEs in wildlife from Europe, Australia, and the Arctic (Law et al. 2003), and levels of PBDEs were on the rise in North American environment (Alaee 2001; Norstrom et al. 2002).

In general, more than $90 \%$ of persistent organic pollutants released into the environment would return to the soil as their major sink (Jones and Voogt 1999). Soil could be the second source for the pollutants to re-volatize into the environment (Zhang and Tao 2008). People should pay more attention on the pollutants' behavior in soil especially in agricultural soil which is tightly connected with human health. As we have 
known from previous researches, PBDEs are released in large amount from various traditional e-waste recycling operations, such as dismantling electronic equipment, plastic peeling and melting, melting circuit boards over open fires, and using acid chemical strippers to recover gold and other metals. It was thought e-waste recycling operations had already introduced PBDEs to the surrounding agricultural area (Huang et al. 2010; Wang et al. 2014a), and the recycling activity was the key contribution to high PBDE level in farmland soil (Dong et al. 2014), which may result in residents' exposure to PBDEs via consumption of local food. Researches are necessary to understand the PBDEs' behavior and influencing factors in the farmland within e-waste recycling sites.

Qingyuan City, which is one of the biggest recycling sites in the world, has much interest on PBDE study. Luo compared the PBDEs concentrations in roadside and farmland soils from Qingyuan and discussed possible source profiles (Luo et al. 2009). Wang analyzed the PBDE concentration in Longtang Town and got the total concentration of PBDEs in soil ranged from 4.8 to $533.0 \mathrm{ng} / \mathrm{g}$ dry weight (Wang et al. 2011). In 2014, Cheng et al. (2014) compared PBDEs in soils from paddy field, peanut field, e-waste recycling site, and reference site and found significant correlation between PBDEs with total organic carbon content in soils. The authors found that the total concentration of PBDEs in this region was at a high level and had resulted in substantial human exposure (Wang et al. 2014a, b).

We are aware of many researches that have examined on temporal dynamics of PBDEs concentrations in various kinds of soils, however the accumulation of PBDEs in farmland soil and the influence of crop rotation were not been studied much yet. Farmland soil is frequently processed including being ploughed and irrigated and fertilized to keep good quality and high production, and crops are always rotating planted according to the crop growth periods and climate conditions. Frequent dry and wet changes in soil may result in changes of the behavior of POPs. For the first time in this study, we took into account the crop rotation process when investigating the dynamic of PBDEs accumulation level in farmland soils. The research contents of this study are firstly to learn the current PBDEs pollution in farmland soils from the study region. Secondly, to investigate the correlation of PBDE concentrations in farmland soil with soil organic carbon contents. Finally, to study the temporal dynamic of PBDEs concentration in the farmland soil considering the influence of crop rotation.

\section{Material and methods}

\section{Study area and sample collection}

The sampling site is located at Qingyuan City, one of the biggest e-waste recycling sites in the world, which is $70 \mathrm{~km}$ northeast of Guangzhou, South China. This region houses more than 1300 dismantling and recycling workshops within two administrative towns, Longtang and Shijiao, and our study area is designated at the right side of North River holding two main e-waste recycling towns of Longtang and Shijiao inside. The total sampling area is $140 \mathrm{~km}^{2}$ (Fig. 1).

To investigate the current spatial distribution of PBDEs in agricultural soils in the study area, we designed to collect one farmland soil samples at every $1 \mathrm{~km}$ grid intersect throughout the study region. Take 1A for example, a rice field not smaller than $100 \mathrm{~m} \times 100 \mathrm{~m}$ was selected inside the $1-\mathrm{km}$ grid, at four uniformly distributed angles in the field, four subsamples were collected and mixed to make the soil sample $1 \mathrm{~A}$, which was illustrated in Fig. 2a. In the laboratory, the soil samples distributed inside the $2 \mathrm{~km} \times 2 \mathrm{~km}$ square, e.g., $1 \mathrm{~A}, 1 \mathrm{~B}, 1 \mathrm{C}$, and $1 \mathrm{D}$, were ground and mixed homogeneously to make the compositive sample CS1 for PBDEs analysis, which was illustrated in Fig. 2b. As some places in the sampling grids were occupied by water or hills, farmland soil samples were hard to get and had to be abandoned. Thus, finally, we got a total of 121 farmland soil samples and 35 compositive soil samples, CS1 CS35, which were illustrated in Fig. 1 for the location and sampling point map.

To investigate the dynamic of PBDEs concentrations in farmland soil considering the crop rotation influence, we selected a cultivated land near Dayougang which was upwind and far from e-waste dismantling source. We collected four to eight soil samples at the beginning of each crop rotation period, and collected air and particle samples near the site simultaneously. The dynamic of PBDE concentrations in the farmland soil and the corresponding changes of total organic carbon (TOC) and air PBDEs deposition were analyzed.

A stainless steel spade was used to collect the upper layer soil at a depth of $0-15 \mathrm{~cm}$ and each sample was about $1 \mathrm{~kg}$ of weight. All the soil samples were wrapped with aluminum foil and put into polythene zip-bags and transported back to the laboratory. Air samples were collected using a medium volume air sampler (KC-300, Laoshan Electronic Technology Co., China) and each for a 24-h period. The gaseous and particulate species were retained with one attached polyurethane foams (PUFs, $6.5 \mathrm{~cm}$ in diameter and $10.0 \mathrm{~cm}$ in length, Laoshan Electronic Technology Co., China) and one glass fiber filter (GFF, $90 \mathrm{~mm}$ in diameter, Pall Co., USA), respectively. Before use, PUFs were extracted with acetone for $24 \mathrm{~h}$ and further applied with a mixture of acetone and hexane $(1: 1, v: v)$ for $24 \mathrm{~h}$ for cleaning purposes. The GFFs were baked for $6 \mathrm{~h}$ at $450{ }^{\circ} \mathrm{C}$ to remove any organic contaminants.

The soil samples were air-dried and ground to pass 200 and 40 mesh sieves separately. The 200 mesh part was prepared for TOC analysis and the 40 mesh part for PBDE compounds analysis. The dried soil samples were saved in $250-\mathrm{mL}$ solvent-cleaned amber jars at room temperature for further 


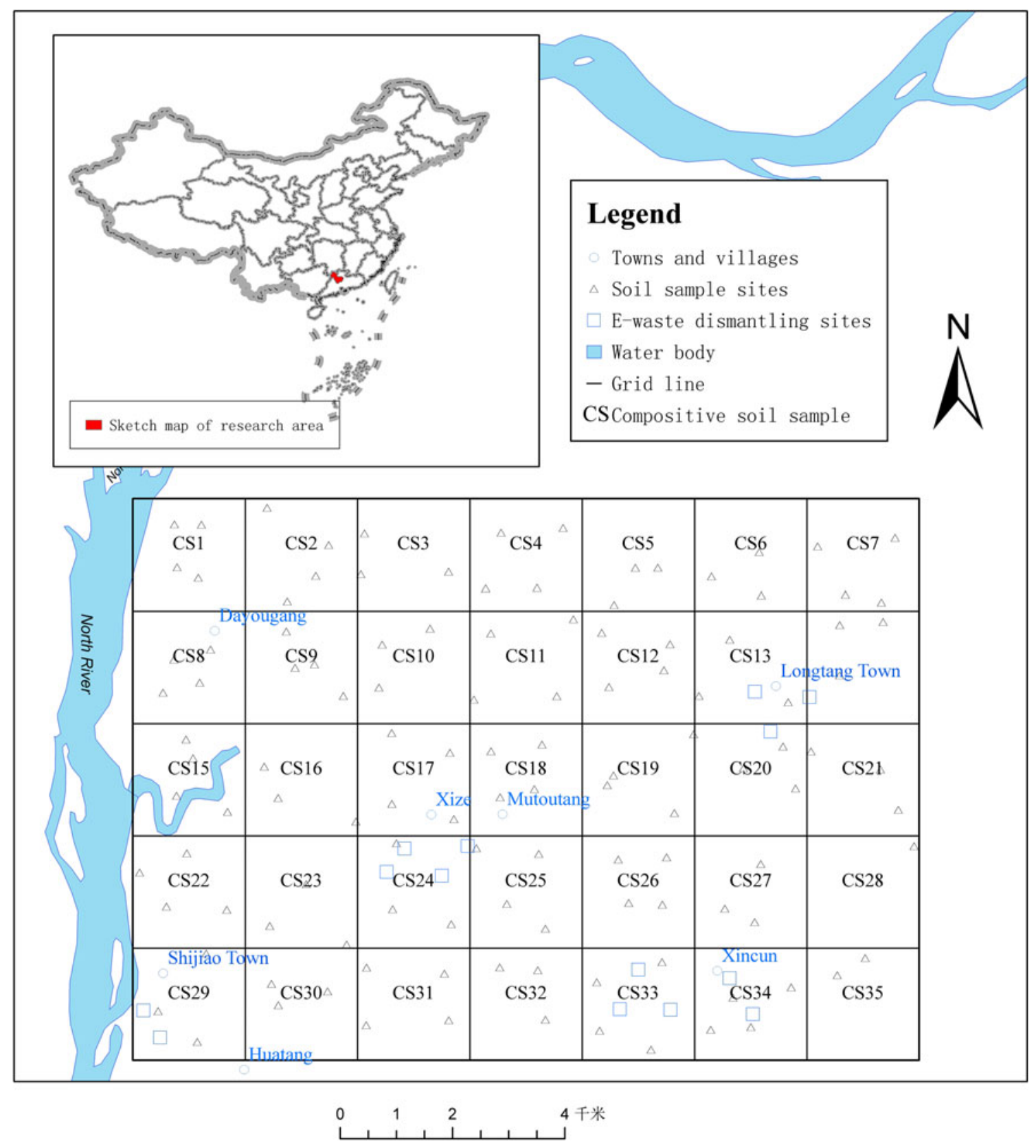

Fig. 1 Location of the study area in the city of Qingyuan Guangdong, China

chemical analysis. PUF and fiber filter samples were put in standard solvent-cleaned amber jars and stored at $-20^{\circ} \mathrm{C}$ before process and analysis. All samples were analyzed within 30 days.

\section{Materials and chemicals}

A standard mixture of 14 PBDE congeners containing PBDEs-17, -28, -71, -47, -66, -100, -99, -85, -154, $-153,-138,-183,-190,-209$ with the concentrations were $1.0 \mathrm{mg} / \mathrm{mL}$ (except BDE 209, which is 5.0 $\mathrm{mg} / \mathrm{mL}$ ) was purchased from Accustandard Co. Single standards of PCB 209 and ${ }^{13} \mathrm{C}-\mathrm{PCB} 141$ were purchased from Cambridge Isotope Laboratories and used as surrogates.

Analytical grade silica gel (100-200 mesh) and aluminum (100-200 mesh) and sodium sulfate were purchased from Anpel Co., China. Silica gel and aluminum were baked for $6 \mathrm{~h}$ at $450{ }^{\circ} \mathrm{C}$ to remove any organic contaminants, and then activated at $160^{\circ} \mathrm{C}$ for $12 \mathrm{~h}$ and stored in a desiccator. Sodium 
Fig. 2 Soil sample collection and analysis design. a Single sample collected in rice field; $\mathbf{b}$ composite sample for PBDE analysis

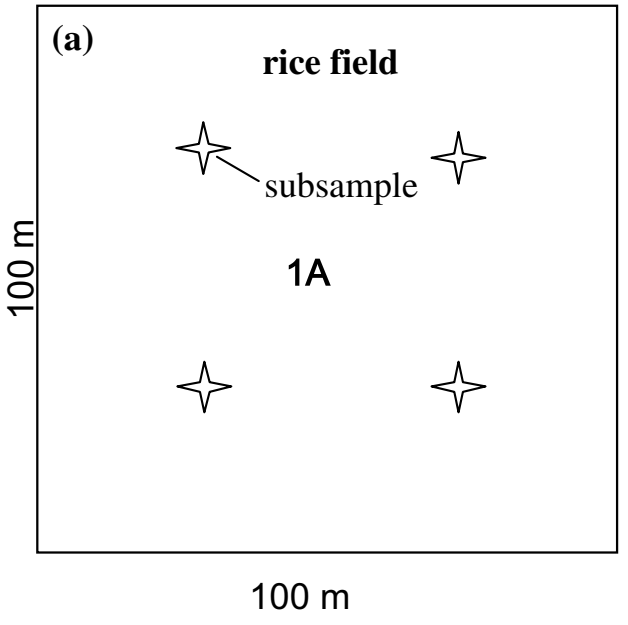

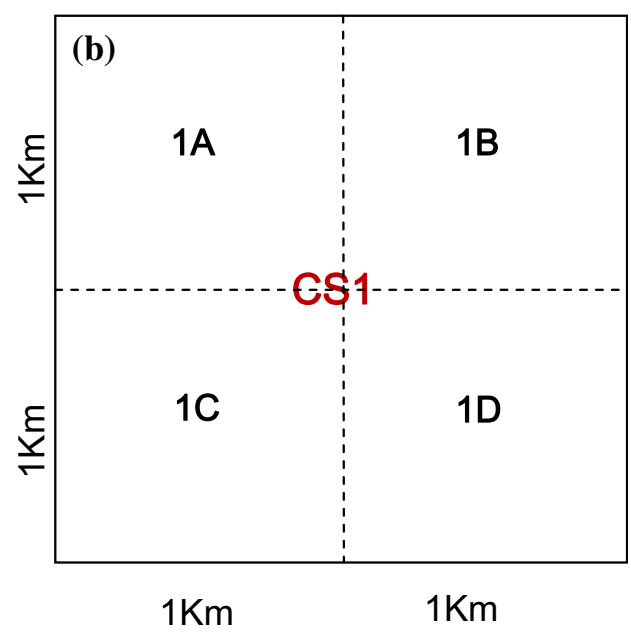

sulfate was baked for $4 \mathrm{~h}$ at $600{ }^{\circ} \mathrm{C}$ before use. All organic solvents used in the analysis were of HPLC grade, including $n$-hexane, dichloromethane (DCM), and acetone (J.T. Baker Co., USA).

\section{Sample extraction and clean-up}

PBDEs were analyzed according to a previously published method (Luo et al. 2009) with slight modification. In brief, soil and particle samples were spiked with ${ }^{13} \mathrm{C}-\mathrm{PCB} 141$ (40 ng per sample) and then Soxhlet-extracted with a mixture of acetone and hexane $(1: 1 v: v)$ for $24 \mathrm{~h}$. Concentrated extracts were cleaned on a $10 \mathrm{~mm}$ i.d. silica/alumina column packed, from the bottom to top, with $3 \%$ deactivated aluminum oxide $(6 \mathrm{~cm}), 3 \%$ deactivated neutral silica gel $(2 \mathrm{~cm}), 33 \%$ sodium hydroxide silica $(5 \mathrm{~cm}), 3 \%$ deactivated neutral silica gel $(2 \mathrm{~cm}), 44 \%$ sulfuric acid silica $(8 \mathrm{~cm})$, and anhydrous sodium sulfate $(1 \mathrm{~cm})$. The column was eluted with $70 \mathrm{ml}$ of hexane:dichloromethane $(1: 1, v: v)$, and the extract was concentrated with a rotary evaporator to a small volume, further concentrated to near dryness under a gentle nitrogen flow, and redissolved in $500 \mu \mathrm{L}$ of hexane.

PUF samples were extracted and cleaned according to Qi et al. (2014) with slight modification. In brief, PUF samples were Soxhlet-extracted with a mixture of cyclohexane and hexane $(1: 1, v: v)$ for $16 \mathrm{~h}$. Then, the extracts were purified with a SPE LC-Si column, and the final extract volume was concentrated to $1.0 \mathrm{~mL}$ by evaporation and a gentle stream of nitrogen.

\section{PBDE analysis}

All congeners were analyzed using Agilent 6890-5975C gas chromatography mass spectrometry (GC-MS) with negative chemical ionization (NCI) in selected ion monitoring (SIM) mode equipped with a DB-5 HT column (15 $\mathrm{m} \times 0.25 \mathrm{~mm} \times 0.1 \mu \mathrm{m}, \mathrm{J} \& \mathrm{~W}$ Scientific). Methane was used as a chemical ionization moderating gas and helium as the carrier gas at a flow rate of $1 \mathrm{~mL} \mathrm{~min}$.
The chromatographic conditions for the PBDE congeners were as follows: $110{ }^{\circ} \mathrm{C}$ for $5 \mathrm{~min}, 110{ }^{\circ} \mathrm{C}$ to $200{ }^{\circ} \mathrm{C}$ $\left(20{ }^{\circ} \mathrm{C} / \mathrm{min}\right), 200{ }^{\circ} \mathrm{C}$ to $280{ }^{\circ} \mathrm{C}\left(10{ }^{\circ} \mathrm{C} / \mathrm{min}\right), 280{ }^{\circ} \mathrm{C}$ to $305^{\circ} \mathrm{C}\left(20^{\circ} \mathrm{C} / \mathrm{min}\right)$, and held for $10 \mathrm{~min}$. The quadrupole, ion source, and interface temperatures were set at 150 , 150 , and $250{ }^{\circ} \mathrm{C}$, respectively. Selected ion monitoring of the two bromide ions at $\mathrm{m} / \mathrm{z} 486.7$ and 488.7 was used to detect BDE-209, and at $m / z 79$ and 81 for the other PBDE congeners. The ${ }^{13} \mathrm{C}$-PCB 141 was detected at $\mathrm{m} / \mathrm{z}$ 372 and 374. The identifications for all chemicals were confirmed, and concentrations were measured using an external quantification standard containing known amounts of all the target PBDE congeners.

\section{Quality assurance and quality control}

A procedural blank, field blank, and spiked blank, consisting of all the chemicals used in the soil extraction process, were analyzed after every eight samples to determine if any contamination occurred during sample collection, extraction, or analysis. All blank controls contained no detectable amounts of the target substances. Recoveries for the spiked blanks were 64.0-124.0\% for soils and particles, and 76.0 $115.0 \%$ for PUFs. Surrogate recovery for ${ }^{13} \mathrm{C}-\mathrm{PCB} 141$ was $99.1 \pm 8.5 \%$. Quantification was performed using the external calibration method based on a seven-point calibration curve $(0.1,0.5,1.0,5.0,10.0,20.0,50.0,100.0 \mathrm{ng} / \mathrm{mL})$ for individual component. The correlation coefficients of the calibration curves were greater than 0.999 for the 13 PBDE compounds (PBDE-17, -28, -71, -47, -66, -100, -99, -85, $154,-153,-138,-183,-190)$ and was 0.997 for BDE209. Instrumental detection limits (IDLs) were 0.04-0.12 ng for the 13 PBDEs and $1.0 \mathrm{ng}$ for BDE-209. Method detection limits (MDLs) in soil were $0.01-0.03 \mathrm{ng} / \mathrm{g}$ for the 13 PBDEs and $0.25 \mathrm{ng} / \mathrm{g}$ for BDE-209. Concentrations reported of PBDEs were not corrected by the recovery rates. PBDE concentrations were expressed as $\mathrm{ng} / \mathrm{m}^{3}$ in particulate and PUF samples, and ng/g of dry weight in soil samples. 


\section{Total organic carbon analysis}

Briefly, about $2-10 \mathrm{mg}$ of dry soil (particle size $<0.074 \mathrm{~mm}$ ) was treated with 1 2 drop of $\mathrm{HCl}$ to remove inorganic carbon, which was then washed with Milli-Q water until achieving a neutral $\mathrm{pH}(7.0 \pm 0.2)$, and was dried for $2 \mathrm{~h}$ at $100^{\circ} \mathrm{C}$. Total organic carbon (TOC) in the soil sample was then quantified by flash combustion at $1000{ }^{\circ} \mathrm{C}$ followed by thermic conductivity detection with a high frequency infrared $\mathrm{C}$ and $\mathrm{S}$ elemental analyzer (HIR944, Wuxi High Speed Analyzing Instrument Co., China). The method detection limit (MDL) was $0.034 \%$. All values were normalized to the initial mass of the sample prior to any treatment.

\section{Statistical analysis}

Statistical evaluations including case summary report and statistical correlation analysis were performed using SPSS 16.0 (AnalystSoft Inc.; Vancouver, BC, Canada). Pearson productmoment correlation coefficient was used for correlation analysis between the concentration of TOC and PBDEs, statistical $t$ test was used to compare means of TOC value from dry and wet land, and Kruskal-Wallis $H$ test was used to test the consistency of the PBDE profiles in the particulate phase, gas phase, and soil. The location of study area and sampling points and the spatial distribution of PBDE concentrations and TOC contents were plotted using ArcGIS 10.2 (ESRI, Redlands, CA, USA), Kriging interpolation was used in plotting the distribution map.

\section{Results and discussion}

\section{Concentration of PBDEs in Qingyuan farmland soils}

The 14 PBDE congeners mentioned above were quantified. The total concentration of PBDEs ranged from 1.8 to $89.3 \mathrm{ng} /$ g dry weight, with the averaged concentration $19.1 \pm 20.1 \mathrm{ng} / \mathrm{g}$ dry weight. Detailed statistical information of PBDE concentrations is shown in Table 1.

Comparing with other e-waste dismantling sites, the total PBDE concentrations in agricultural soil in Long-Shi Region in this study were generally at least 1 magnitude lower. The total PBDEs near e-waste processing sites were 2.96 to $200 \mathrm{ng} / \mathrm{g}$ with an average of $65.2 \mathrm{ng} / \mathrm{g}$ in Taizhou (Dong et al. 2014) and reaches $10-6535 \mathrm{ng} / \mathrm{g}$ with an average of $1588 \mathrm{ng} / \mathrm{g}$ in Guiyu (Zhang et al. 2014). One reason is that the amount of e-waste dismantled in Long-Shi region is much less than that in Taizhou and Guiyu as well the PBDEs released to the environment. It was reported that approximately 1.7 million tons, 2.2 million tons, and more than 3.0 million tons of e-wastes were dismantled annually in Long-shi region, Taizhou, and Guiyu, respectively (Chen et al. 2012; Alaee
Table 1 Concentration of PBDE congeners in soil samples (ng/g dry weight) $(n=35)$

\begin{tabular}{llllll}
\hline & NOD $^{*}$ & Min & Max & Median & S.D. \\
\hline BDE17 & 21 & n.d. & 0.9 & 0.2 & 0.2 \\
BDE28 & 22 & n.d. & 0.6 & 0.2 & 0.1 \\
BDE71 & 22 & n.d. & 0.9 & 0.2 & 0.2 \\
BDE47 & 33 & n.d. & 1.5 & 0.2 & 0.4 \\
BDE66 & 17 & n.d. & 0.3 & 0.1 & 0.1 \\
BDE100 & 29 & n.d. & 1.0 & 0.2 & 0.2 \\
BDE99 & 35 & 0.1 & 1.6 & 0.2 & 0.4 \\
BDE85 & 29 & n.d. & 1.1 & 0.1 & 0.2 \\
BDE154 & 35 & 0.1 & 1.8 & 0.2 & 0.5 \\
BDE153 & 34 & n.d. & 2.1 & 0.1 & 0.4 \\
BDE138 & 15 & n.d. & 1.4 & 0.2 & 0.3 \\
BDE183 & 28 & n.d. & 9.3 & 0.2 & 1.7 \\
BDE190 & 29 & n.d. & 3.2 & 0.2 & 0.7 \\
BDE209 & 35 & 1.2 & 80.8 & 10.3 & 20.1 \\
Sum non-BDE209 PBDEs & & 0.5 & 16.7 & 1.8 & 2.9 \\
Sum PBDEs & & 1.8 & 89.3 & 13.0 & 20.8 \\
\hline
\end{tabular}

NOD number of samples above detection limit

et al. 2003; Wang and $\mathrm{Xu}$ 2014). Besides, the types of wastes and the dismantling manner are different among these regions. People in Long-Shi region tend to dismantle capacitors and wire cables (mostly containing PCBs), while workshops in Guiyu tend to dismantle PBDE-enriched devices such as computers and television sets, which may somehow result in different pollution levels of PBDEs in soils (Yang et al. 2008).

PBDE concentrations in agricultural soil in this study were also much lower than that in other kinds of soil, such as soils from residential area and soils on roadside (Liu et al. 2013; Luo et al. 2009; Leung et al. 2007). A study on Shanghai agricultural sites showed a total of 44 PBDE congeners' concentration averaged $429 \mathrm{ng} / \mathrm{g}$ (range from 129 to $1245 \mathrm{ng} / \mathrm{g}$ ) (Jiang et al. 2012). In addition, our results were remarkably higher than those in grassland soils. PBDEs in UK grassland soil has an average of $0.61 \mathrm{ng} / \mathrm{g}$ (range from 0.065 to $6 \mathrm{ng} / \mathrm{g}$ ) (Hassanin et al. 2004), and even from the large recycling town Guiyu, PBDEs in a background grassland soil was as low as 2-6.2 ng/g (Leung et al. 2007). PBDEs in agricultural soil and other kinds of soil from e-waste recycling sites by literatures are listed in Table 2.

As consistent with other studies, BDE209 was the predominant congener accounting for a range of 48 94\% of total PBDEs, with the following congeners are BDE47, BDE183, and BDE99, accounting for about $9 \%$ of total PBDEs. The result indicated that deca- and penta-products are the most highly dismantled wastes in this region. It was also found that BDE209 accounts for a higher proportion in farmland soil than in e-waste dumping and burning sites with much greater PBDE concentrations. According to Wang et al. 
Table 2 PBDEs concentration in agricultural soil from various e-waste recycling sites (ng/g dry weight)

\begin{tabular}{llll}
\hline Description & $\begin{array}{l}\text { Averaged } \\
\text { concentration } \\
(\text { min to max })\end{array}$ & Study area & Reference \\
& $19.0(1.8-89.3)$ & Qingyuan & This study \\
\hline Agricultural soil $(n=35)$ & $31.7-143$ & Qingyuan & Cheng et al. 2014 \\
Paddy and peanut surface soil $(n=4)$ & $3.83-735$ & Qingyuan & Wang et al. 2014a \\
rhizosphere soil $(n=10)$ & $0.76-198$ & & \\
Non-rhizosphere soil $(n=10)$ & $34.1(17.0-51.7)$ & Qingyuan & Wang et al. 2011 \\
Vegetable field $(n=10)$ & $15.6(9.7-21.7)$ & & \\
Paddy field $(n=14)$ & $26.5(15.2-45.7)$ & & \\
Deserted soil $(n=4)$ & $296(151-533)$ & & \\
Open burning site $(n=5)$ & $42.2(5.1-207.4)$ & Qingyuan & Luo et al. 2009 \\
Farmland soil near dismantling workshop $(n=18)$ & $39.1(2.9-195.1)$ & Guiyu & Leung et al. 2007 \\
Farmland soil near open burning sites $(n=15)$ & $48.2(34.7-70.9)$ & & \\
Rice field $(n=3)$ & $3.8(2.0-6.2)$ & & \\
Reservoir $(n=3)$ & $1440(893-2890)$ & & \\
printer roller dump site $(n=3)$ & 10.70 & Guiyu & Liu et al. 2013 \\
Reservoir $(n=4)$ & 11.42 & & \\
paddy soil $(n=15)$ & 22.84 & & \\
residential area $(n=33)$ & 302.06 & Taizhou & Dong et al. 2014 \\
E-waste recycling site $(n=10)$ & $1588(10-6535)$ & Cai and Jiang 2006 \\
Agricultural soil $(n=46)$ & $65.2(2.96-200)$ & Thiyu & \\
Farmland soil $(n=45)$ & $945.2(857.5-991.2)$ & Taizhou & \\
Soils in transformer recycling site $(n=4)$ & & & \\
\hline
\end{tabular}

(2011) and Leung et al. (2007), BDE209 accounts for $42 \sim 52 \%$ of the total PBDEs in the soils from e-waste burning sites, while in residential area and agricultural area, the proportion increased to 73 75\% (Wang et al. 2014a).

\section{Spatial distribution of PBDEs}

In the study region, the total PBDEs were concentrated in areas with active and deserted dismantling workshops scattered around, such as Longtang Town, Xincun village, Shijiao Town, etc., and dispersed with distance from the source, as shown in the distribution map in Fig. 3. It meant there was a significant introduction of PBDEs from the e- waste operations to the surroundings, which also validated by many other studies (Zhao et al. 2009; Li et al. 2011; Wang et al. 2011). Zhao et al. (2009) found that PBDEs from the e-waste recycling area diffused into the surrounding regions and showed a halo effect up to $74 \mathrm{~km}$. Li et al. (2011) collected soil samples in four directions around an ewaste site within $40 \mathrm{~km}$ radius and found the PBDEs concentration in soils decreased with increasing distance from the source. It was generally concluded that the highly bromine substituted PBDEs such as BDE209 would decrease quicker with distance than the less brominated congeners, indicating very low transportability for the highly bromine substituted PBDEs (Liu et al. 2013; Ruiz-Fernández et al. 2014). While
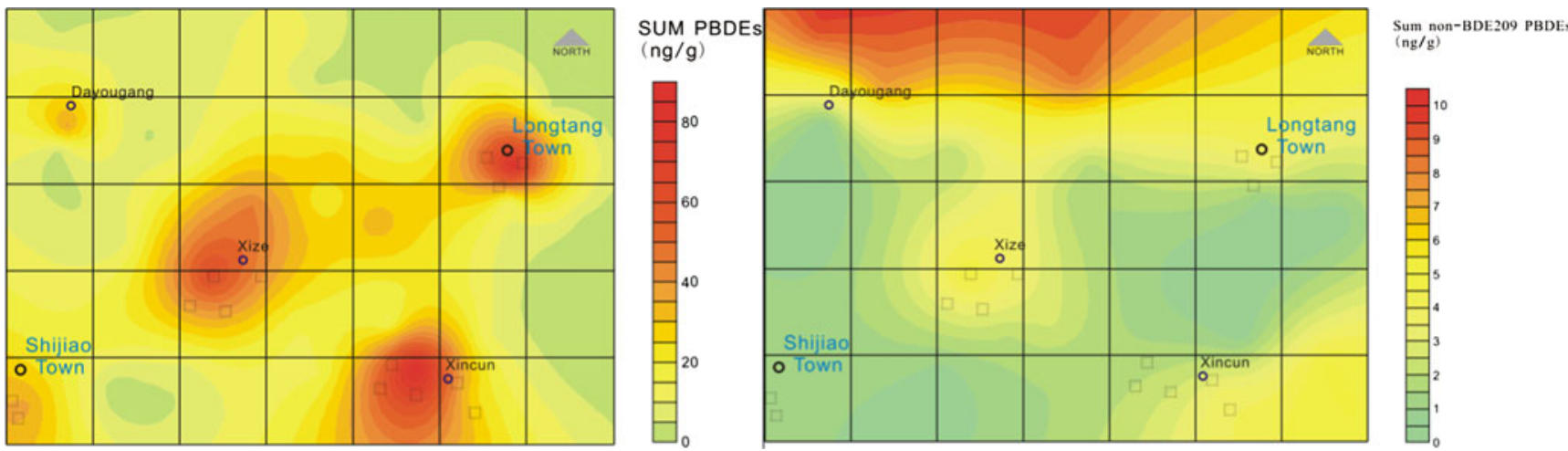

Fig. 3 Spatial distribution of concentration of total PBDEs (left) and Sum non-BDE209 PBDEs (right) in the farmland soil 
Fig. 4 Spatial distribution of TOC in surface soil
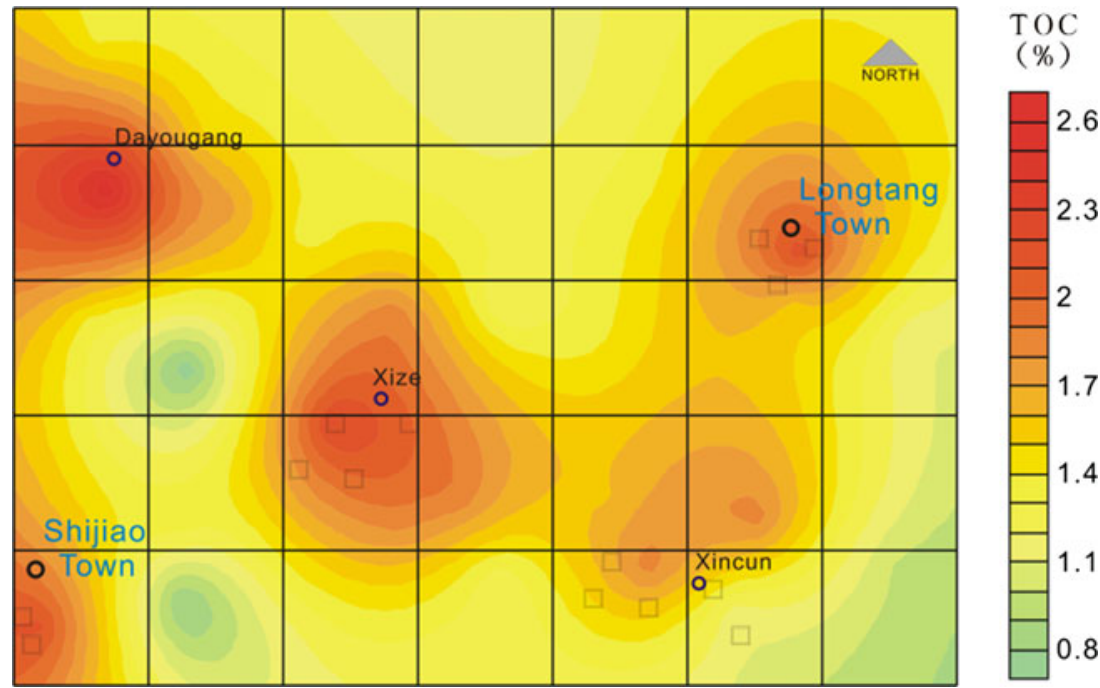

in the short range transport mode, the trends of highly and less brominated PBDEs both show subtle changes with no significant differences (Li et al. 2011).

As shown from Fig. 3, the distribution profile of nonBDE209 compounds was significantly different with that of BDE209, which was highly consistent with total PBDEs. Non-BDE209 compounds were not so correlated with ewaste source as BDE209, but focus on the northern part of the study region, which was taken as controlled area and closer to Qingyuan City. The distribution pattern may reflect the degradation of BDE209 and transportation of non-BDE209 compounds through traffic.

\section{TOC content and the correlation with PBDEs}

The content of total organic carbon (TOC) in this study is between 0.27 and $2.95 \%$ with an average of $1.54 \% \pm 0.58 \%$ for all the soil samples. TOC contents in paddy soils are statistically higher $(p<0.01)$ than that in dry fields, which are $1.62 \% \pm 0.56 \%$ and $1.31 \% \pm 0.55 \%$ separately, but both are lower than TOC contents in forest soils (averaged $13.85 \%$ referred to Parolini et al. 2013). The highest TOC value was found in a paddy field located at a village near Dayougang, and the lowest one was found in a small piece of vegetable field under a hill in Shijiao Town. The overall TOC distribution map is shown in Fig. 4.

It is commonly observed that concentrations of hydrophobic organic pollutants including PAHs and PBDEs in soil are controlled by soil TOC content, with higher pollutants' concentration accompanied with high TOC content (Wilcke et al. 2003; Zhang et al. 2006; Nam et al. 2008). However, some researchers found different trends existed when analyzing the pollution level of organic pollutants vs soil TOC under certain conditions. Eguchi et al. (2013) found that in the dumping sites with higher PBDE levels the correlation is not as significant as with those from agricultural soil and background area. In another study carried out by Jiang et al. 2012, soil TOC was observed poorly correlated with highly brominated PBDEs such as BDE209 and BDE203, while significantly correlated with low brominated PBDEs. In this study, significant positive correlation $(r=0.704, p<0.01)$ was observed between TOC and BDE209, while the related coefficients between TOC and other PBDE compounds was
Fig. 5 The correlation between TOC and total PBDEs (left side) and TOC and Sum non-BDE209 PBDEs (right side)
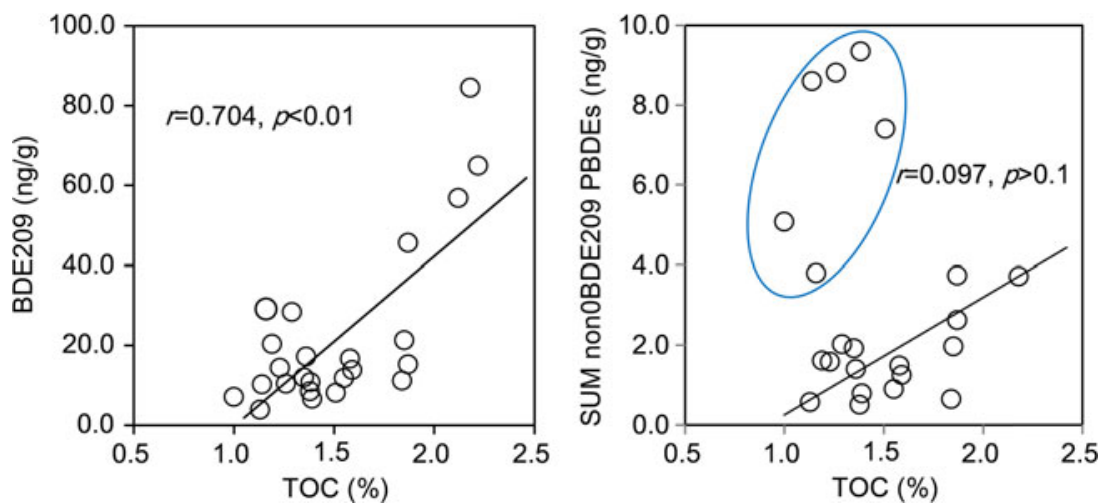
Fig. 6 Spatial distribution of Sum PBDEs per TOC content

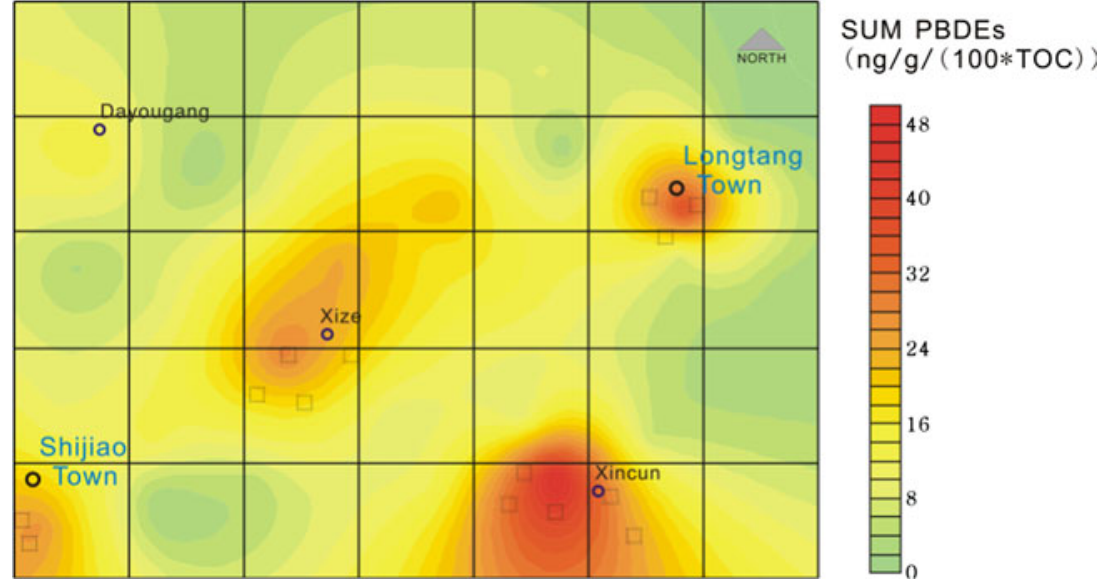

poor, with the correlation factor $r$ below 0.1 and $p$ value above 0.1, seen in Fig. 5. But with the exception of the sites where the sum concentrations of Non-BDE209 PBDEs were higher than $4.0 \mathrm{ng} / \mathrm{g}$, the correlation became significant, with $r=0.612$ at $p<0.05$ level. It was found that the excluded sites were all located at highroad side, where traffic factors may cover the TOC impact on the distribution of non-BDE209 PBDE compounds.

For the spatial distribution of soil PBDEs, TOC also act as an important impact factor, especially on the PBDEs accumulation in agricultural soil from background area. When the compounds' concentration was standardized by TOC value, the higher level zones of Sum PBDEs shifted from the original location on the distribution map, seen in Fig. 6. By removing the influence of soil TOC content, PBDEs in the farmland soil from background area (here Dayougang was taken as background) showed no more concentration, while significant accumulation of PBDEs still existed in e-waste dismantling areas, including Longtang, Xize, Xincun, and Shijiao Town. It was indicated that in the area near e-waste shops, the pollutant source contributed more to the soil PBDEs accumulation.

\section{Temporal trends of PBDEs in farmland soils considering crop rotation process}

In the study area, the farmland soil has experienced long term paddy-peanut rotation pattern. During a whole crop rotation cycle including 4 land use periods from April 2012 to April 2013, that are the previous year early paddy period (PEP), autumn peanut period (AP), fallow land period (FL), and the next year early paddy period (NEP), corresponding samples of soil and air were collected at the beginning of each rotation period. Figure 7 showed the temporal trends of PBDEs in the gas phase, particulate phase and soil during the rotation cycle, and TOC values for the four rotation periods were given too.

Generally speaking, persistent organic pollutants in surface soil are usually eliminated through the processes of volatilization, biodegradation, transportation to deeper soil and the physical and biological processes (Jones 1991; Law et al. 2006). PBDE compounds in farmland soil go through those processes as well and finally disappeared from the environment. Paddy soil are irrigated more frequently than dry land soil, and are carried draining and sunning 2 3 times to improve the permeability of the soil and help rice plant strong and mature at time. So the organic compounds in paddy soil would undergo more violent changes of some environmental

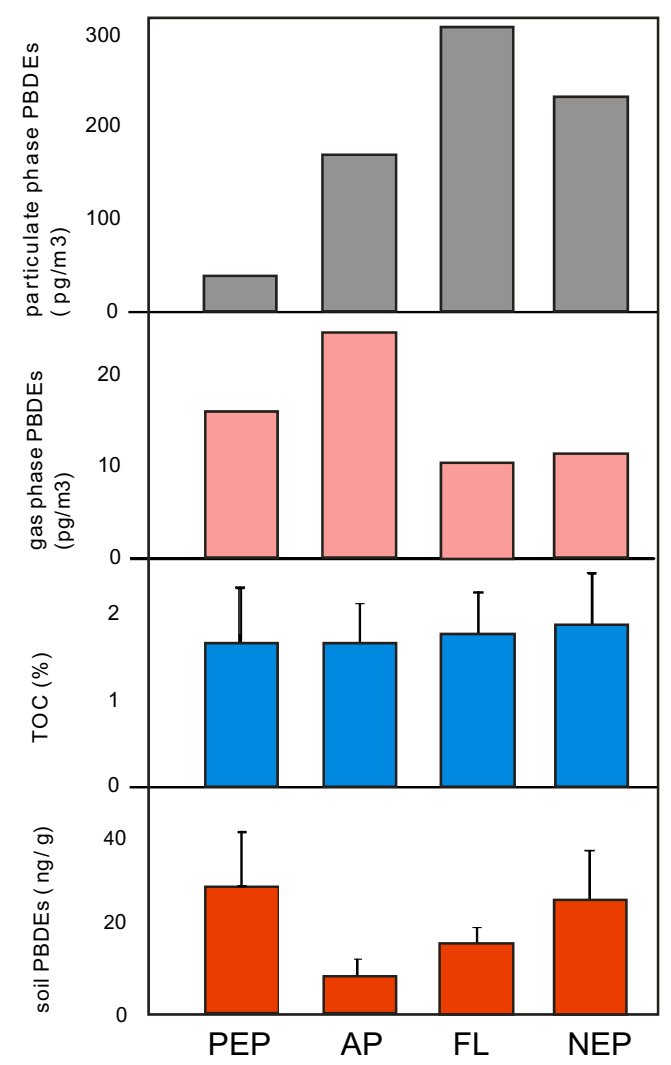

Fig. 7 Comparison of PBDE dynamics among farmland soil and other factors ( $P E P$ previous year early paddy period; $A P$ autumn peanut period; $F L$ fallow land period; $N E P$ the next year early paddy period) 
factors such as humidity, $\mathrm{pH}$, redox state, and microorganisms, resulting in the PBDE compounds fluctuate violently. One of our previous studies showed that the PAHs concentrations in paddy soil decreased continuously during the whole growth period (Jiao et al. 2007). In this study, as shown in Fig. 7, The PBDE concentration in the farmland soil was highest $(25.3 \pm 11.4 \mathrm{ng} / \mathrm{g}$ dry weight) in April when early paddy had been transplanted for 1 or 2 weeks. When the crop rotated to autumn peanut in August and the land is turning dry, the PBDEs concentration in farmland soil reached the lowest level which was $8.1 \pm 1.2 \mathrm{ng} / \mathrm{g}$ dry weight. Many studies showed that PBDEs in water field may be much lower than that in dry field (Cheng et al. 2014; Wang et al. 2011), and most PBDEs in agricultural soil are accumulated in the rhizosphere area (Wang et al. 2014b). But the results of this study showed a trend that the total PBDEs concentration in farmland soil decreased from rice transplanting in April to rice harvesting in August, but increased to a higher level at fallow land period and returned to the highest level in early paddy period when the soil was totally wet at the beginning of the next year. The temporal trend of PBDE concentrations in farmland soil showed a significant dependence on the wet or dry status of the soil during various crop growing periods. So when studies were carried to compare and study how the compounds behave among different kinds of soil, the sampling time could play an important role on the results.

Figure 7 also showed that the highest particle-phase PBDEs concentration occurred in November during the fallow land period and the highest gas-phase PBDEs concentration occurred in August during the autumn peanut period. The trends of the PBDEs in farmland soil in this study are not consistent with that in air, neither for the gas-phase nor the particle-phase PBDEs. TOC content kept relatively steady through the four periods, which were $1.83 \pm 0.67 \%, 1.86$ $\pm 0.43 \%, 1.89 \pm 0.48 \%$ to $1.99 \pm 0.54 \%$ sequentially. By the Kruskal-Wallis $H$ test, the differences of PBDE profiles in soil, particulate phase, and gas phase among each rotation period were not significant, with the significant factors 0.177 , 0.711 , and 0.238 separate. There were no significant temporal trends for PBDEs profiles in air and soil either. It was concluded that the dynamics of PBDEs in the farmland soil is influenced by multiple, interacting factors, and not clearly related to the atmospheric deposition and the organic carbon content of the soil but possibly related to the microenvironmental conditions changed by crop rotation process.

\section{Conclusions}

(1) PBDE concentrations in farmland soil from Longtang and Shijiao region were averaged $19.1 \pm 20.7 \mathrm{ng} / \mathrm{g}$ dry weight, which were statistically lower than that from other e-waste recycling regions.
(2) TOC played an important role especially on the PBDEs accumulation in agricultural soil from background area, while in the area near e-waste shops, the pollutant source contributed more on the soil PBDEs accumulation.

(3) The temporal trends of PBDEs in farmland soil were not consistent with that of TOC and atmospheric PBDEs, but were highly variable and dependent on many interacting factors controlled by crop rotation processes.

Acknowledgments This work was financially supported by the National Natural Science Foundation of China (41171370, 41171373) and the China Geology Survey Project (1212011220058).

\section{References}

Alaee M (2001) Levels and trends of PBDEs in North American environment. The second international workshop on brominated flame retardants. BFR 2001, Stockholm, pp 131-134

Alaee M, Arias P, Sjödin A, Bergman Å (2003) An overview of commercially used brominated flame retardants, their applications, their use patterns in different countries/regions and possible modes of release. Environ Int 29:683-689

Cai ZW, Jiang GB (2006) Determination of polybrominated diphenyl ethers in soil from e-waste recycling site. Talanta 70:88-90

Chen Y, Li J, Liu L, Zhao N (2012) Polybrominated diphenyl ethers fate in China: a review with an emphasis on environmental contamination levels, human exposure and regulation. J Environ Manag 113:22-30

Cheng Z, Wang Y, Wang S, Luo C, Li J, Chaemfa C, Jiang H, Zhang G (2014) The influence of land use on the concentration and vertical distribution of PBDEs in soils of an e-waste recycling region of South China. Environ Pollut 191:126-131

de Wit CA (2002) An overview of brominated flame retardants in the environment. Chemosphere 46:583-624

Dong Y, Li L, Bie P, Jia S, Wang Q, Huang Z, Qiu X, Zhang J, Hu J (2014) Polybrominated diphenyl ethers in farmland soils: source characterization, deposition contribution and apportionment. Sci Total Environ 466-467:524-532

Eguchi A, Isobe T, Ramu K, Tue MN, Sudaryanto A, Devanathan G, Viet PH, Tana RS, Takahashi S, Subramanian A, Tanabe S (2013) Soil contamination by brominated flame retardants in open waste dumping sites in Asian developing countries. Chemosphere 90:2365-2371

Hassanin A, Breivik K, Meijer SN, Steinnes E, Thomas GO, Jones KC (2004) PBDEs in European background soils: levels and factors controlling their distribution. Environ Sci Technol 38:738-745

Huang H, Zhang S, Christie P, Wang S, Xie M (2010) Behavior of decabromodiphenyl ether (BDE-209) in the soil-plant system: uptake, translocation, and metabolism in plants and dissipation in soil. Environ Sci Technol 44:663-667

Jiang YF, Wang XT, Zhu K, Wu MH, Sheng GY, Fu JM (2012) Occurrence, compositional patterns, and possible sources of polybrominated diphenyl ethers in agricultural soil of Shanghai, China. Chemosphere 89:936-943

Jiao XC, Xu FL, Dawson R, Chen SH, Tao S (2007) Adsorption and absorption of polycyclic aromatic hydrocarbons to rice roots. Environ Pollut 148:230-235

Jones KC (1991) Contaminant trends in soils and crops. Environ Pollut 69:311-325

Jones KC, de. Voogt P (1999) Persistent organic pollutants (POPs): state of the science. Environ Pollut 100:209-221 
Law RJ, Alaee M, Allchin CR, Boon JP, Lebeuf M, Lepom P, Stern GA (2003) Levels and trends of polybrominated diphenylethers and other brominated flame retardants in wildlife. Environ Int 29:757-770

Law RJ, Allchin CR, Boer JD, Covaci A, Herzke D, Lepom P (2006) Levels and trends of brominated flame retardants in the European environment. Chemosphere 64:187-208

Leung AO, Luksemburg WJ, Wong AS, Wong MH (2007) Spatial distribution of polybrominated diphenyl ethers and polychlorinated dibenzo- $p$-dioxins and dibenzofurans in soil and combusted residue at Guiyu, an electronic waste recycling site in southeast China. Environ Sci Technol 41:2730-2737

Li H, Bai J, Li Y, Cheng H, Zeng E, You J (2011) Short-range transport of contaminants released from e-waste recycling site in South China. J Environ Monit 13:836

Liu QL, Jiao XC, Wang XC, Lu GH, Gai N, Yang YL (2013) Spatial distribution of PBDEs in topsoils from electronic waste dismantling sites and the surrounding areas in Guiyu, Guangdong Province. Rock Mineral Anal 31:1006-1014

Luo Y, Luo XJ, Lin Z, Chen SJ, Liu J, Mai BX, Yang ZY (2009) Polybrominated diphenyl ethers in road and farmland soils from an e-waste recycling region in Southern China: concentrations, source profiles, and potential dispersion and deposition. Sci Total Environ 407:1105-1113

Miglioranza KSB, Gonzalez M, Ondarza PM, Shimabukuro VM, Isla FI, Fillmann G, Aizpun JE, Moreno VJ (2013) Assessment of Argentinean patagonia pollution: PBDEs. OCPs and PCBs in different matrices from the RioNegro basin. Sci Total Environ 452:275-285

Nam JJ, Thomas GO, Jaward FM, Steinnes E, Gustafsson O, Jones KC (2008) PAHs in background soils from Western Europe: influence of atmospheric deposition and soil organic matter. Chemosphere 70:1596-1602

Norstrom RJ, Simon M, Moisey J, Wakeford B, Weseloh DVC (2002) Geographical distribution (2000) and temporal trends (1981-2000) of brominated diphenyl ethers in Great Lakes herring gull eggs. Environ Sci Technol 36:4783-4789

Parolini M, Guazzoni N, Comolli R, Binelli A, Tremolad P (2013) Background levels of polybrominated diphenyl ethers (PBDEs) in soils from MountMeru area, Arusha district (Tanzania). Sci Total Environ 452-453:253-261

Qi H, Li WL, Liu LY, Song WW, Ma WL, Li YF (2014) Brominated flame retardants in the urban atmosphere of Northeast China:
Concentrations, temperature dependence and gas-particle partitioning. Sci Total Environ 491-492:60-66

Ruiz-Fernández AC, Ontiveros-Cuadras JF, Sericano JL, SanchezCabeza J, Liong L, Wong W, Dunbar RB, Mucciarone DA, PérezBernal LH, Páez-Osuna F (2014) Long-range atmospheric transport of persistent organic pollutants to remote lacustrine environments. Sci Total Environ 493:505-520

Wang R, Xu Z (2014) Recycling of non-metallic fractions from waste electrical and electronic equipment (WEEE): A review. Waste Manag 34:1455-1469

Wang Y, Luo C, Li J, Yin H, Li X, Zhang G (2011) Characterization of PBDEs in soils and vegetations near an e-waste recycling site in South China. Environ Pollut 159:2443-2448

Wang S, Zhang S, Huang H, Niu Z, Han W (2014a) Characterization of polybrominated diphenyl ethers (PBDEs) and hydroxylated and methoxylated PBDEs in soils and plants from an e-waste area. Chin Environ Pollut 184:405-413

Wang Y, Luo C, Li J, Yin H, Zhang G (2014b) Influence of plants on the distribution and composition of PBDEs in soils of an e-waste dismantling area: evidence of the effect of the rhizosphere and selective bioaccumulation. Environ Pollut 186:104-109

Wilcke W, Amelung W, Krauss M, Martius C, Bandeira A, Garcia M (2003) Polycyclic aromatic hydrocarbon (PAH) patterns in climatically different ecological zones of Brazil. Org Geochem 34:1405-1417

Yang Z, Zheng J, Chen S, Yuan J, Luo X, Luo Y, Mai B (2008) Advantage of researches on environmental pollutions from e-waste treating activities in Guangdong, China. Asian J Ecotoxicol 3:533544 (in Chinese)

Zhang Y, Tao S (2008) Seasonal variation of polycyclic aromatic hydrocarbons (PAHs) emissions in China. Environ Pollut 156:657-663

Zhang HB, Luo YM, Wong MH, Zhao QG, Zhang GL (2006) Distributions and concentrations of PAHs in Hong Kong soils. Environ Pollut 141:107-114

Zhang S, Xu X, Wu Y, Ge J, Li W, Huo X (2014) Polybrominated diphenyl ethers in residential and agricultural soils from an electronic waste polluted region in South China: distribution, compositional profile, and sources. Chemosphere 102:55-60

Zhao YX, Qin XF, Li Y, Liu PY, Tian M, Yan SS, Qin ZF, Xu XB, Yang YJ (2009) Diffusion of polybrominated diphenyl ether (PBDE) from an e-waste recycling area to the surrounding regions in Southeast China. Chemosphere 76:1470-1476 